doing well at work may reflect some degree of bias in selecting day-patients from those presenting with work problems. It may also be suggested that the larger number of respondents, and the significantly smaller number of spoilt or incompletely returned forms from the day-patient sample, point towards a greater involvement in, and commitment to, their past treatment, whereas for out-patients commitment may be more tenuous. Though the results may have been different had a comparable sample of out-patients responded adequately, it is doubtful whether any firm opinions could have been formulated based on such relatively crude measurements. Only a much more detailed, sophisticated investigation, designed to elicit the finer qualitative responses to the two types of approach and their meaning for the patient, can give an answer to whether, in terms of clinical and social gains (rather than in terms of management) patients are at an advantage in day care.

SUSANNE Shapar.

Day Department, Crumpsall Hospital, Manchester 8.

REFERENCES

1. Ferguson, R. S. (1968). B. med. 7., i, 119.

2. Farndale, W. A. J. (1967). New Aspects of the Mental Health Services. Oxford, Pergamon.

3. O'Gorman, G. (1968). Modern Trends in Mental Health and Subnormality. London. Butcerworth.

4. Ferguson, R. S. Personal Communication.

\section{THE LESBIAN PERSONALITY}

\section{DeAr Sir,}

In preparation for a lecture I have just re-read June Hopkins' paper (Journal, December 1969) and my suspicion that her description of personality was simply that of a lesbian who might volunteer for a survey was rekindled. The sample studied was doubly self-selected, latterly by volunteering for study and formerly by joining an active minority group. The author at one stage in her paper recognizes this, but refers on the basis of her study to the average lesbian as being independent. From the paper one could construct the hypothesis that lesbians who are the dominant partners in a relationship are more likely to join active minority groups and more likely to show the traits described in the summary of the paper. Would Sister George have allowed her Alice to volunteer for the survey or even to join a wider group of lesbians?

One does not make a sample more representative of its group by comparing it with controls. It is doubtful whether one can even describe the groups as matched for, although certain factors have been paired, the controls were presumably also volunteers who may have had entirely different motives for volunteering. There is no indication that they belong to other active minority groups. Finally, the description of the personality traits found may be those applicable to a situation in the lesbian partnership and may not be related to status in the wider world.

Highcroft Hospital,

B. H. Fookes.

\section{Erdington,}

Birmingham 23.

Dear Sir,

In the last paragraph of his letter, Dr. Fookes' comment 'One does not make a sample more representative of its group by comparing it with controls' is true. However, he then suggests that the motives of the controls were probably different from those of the subjects. I fail to comprehend the significance of such a statement. I would be very surprised to find 'the motives' of any control group in a study of this kind being queried prior to their selection as subjects. It is difficult to believe they are.

Earlier in his letter he has said, 'From the paper one could construct the hypothesis that lesbians who are the dominant partners in a relationship ... are more likely to show the traits described in the summary ... '. Dr. Fookes has obviously jumped to the conclusion that the majority of the lesbians in the investigation were the dominant partners. Such an assumption is unwarranted, if it is based on my paper. The majority of the 105 lesbians who originally participated in the research came in partner teams to be tested. The 24 selected could just as easily have been 'submissive' partners as 'dominant' ones. There is no way to distinguish, as they were selected explicitly because they most nearly matched the controls in age, intelligence and profession. In any case, I feel that strict role-typing (dominant and submissive) has no real place in the discussion of relationships generally. Roles in relationships change constantly, depending on situations, and we tend to lose sight of this fact when we stereotype the individuals concerned by placing labels on them.

My paper is open to the criticism that I have compared unmarried women with married women. My reason for doing this is that I attempted to ward off any speculation of those women claiming to be heterosexual by using facts, i.e., husband and children, as objective support of their subjective Kinsey ratings. I feared that unmarried heterosexual women might be suspect, particularly if their results (perhaps 